\title{
A PRAGMATIC ANALYSIS OF THANKING STRATEGIES AMONG INDONESIAN EFL LEARNERS BASED ON SOCIAL STATUS AND SOCIAL DISTANCE
}

\author{
Siti Kustini $^{1}$, Iis Sulyaningsih ${ }^{2}$ \\ ${ }^{1}$ State Polytechnic of Banjarmasin \\ ${ }^{2}$ State Polytechnic of Bandung
}

Corresponding e-mail: sitikustinipoliban@gmail.com

\begin{abstract}
This study attempts to investigate thanking strategies used by Indonesian EFL learners based on contextual factors i.e. social status and social distance. The participants were 50 semester three students studying English for Business at a state polytechnic in Bandung. The participants were both male and female, aging from 1920 years old. Data were collected via a Discourse Completion Task (DCT) adopted from Cheng (2005) and analyzed using thanking strategy taxonomy proposed by the same author. The DCT consisted of ten different scenarios describing the most common situations that students may encounter in their college life. The results of this study indicated that the most preferred thanking strategies used by Indonesian EFL learners were thanking, alerters (i.e., title) and positive feelings. In terms of social status and social distance, the findings revealed that thanking and apology strategies were the most used strategies in equal-status with low-familiarity situations. In situations within which learners shared equal-status with high-familiarity, the most strategies employed were thanking and positive feelings. Regarding thanking strategies used in low-status with low-familiarity situations, thanking and repayment strategies seemed to be the most preferred ones.
\end{abstract}

Keywords: thanking, strategies, social status, social distance

\section{Introduction}

Speech act is one of the most fundamental parts of pragmatics. To express themselves, people, in their real day-to-day life interactions, do not only produce utterances containing grammatical structures and words, but perform acts via those utterances as well. Examples of speech acts are refusals, suggestions, apologies, compliments, compliment responses, thanking and so on. One of the most commonly used speech acts is the speech act of thanking. Thanking is realized when the speaker expresses gratitude for the hearer's participation in a prior action that was beneficial to the speaker (Cheng, 2005; Yoosefvand and Rasekh, 2014). Kumar (2001) in Ozdemir \& Rezvani (2010) highlights the significance of expressions of gratitude in the following words: 
"Expressions of gratitude in the normal day-to-day interactions between the members of a society seem obviously to fall in the category of the "social" use of language. Expressions of gratitude and politeness are a major instrument the use of which keeps the bonds between the members of a society wellcemented and strong."

According to many scholars, the speech act of thanking is a universal illocution across languages and cultures (Coulmas, 1981 \& Aijmer, 1996). Aijmer (1996) states that expressing gratitude is considered a stereotypical speech act because the form of thank you or thanks is almost always used by speakers every time they want to express gratitude.

One has to keep in mind that not all expressions using the word 'thank you' refer to gratitude (Eisenstein and Bodman, 1993). They can also refer to other language functions such as compliments and closings in conversations (i.e., Thant's all, thank you), or rejecting an offer (i.e. No, thank you or [Thanks], I'm fine) (Rubin, 1983 in Ozdemir \& Rezvani, 2010). It is also argued that successful performance of this language function may result in positive feelings, whereas failure of expressing gratitude may have negative consequences.

This study is carried out with an attempt to investigate thanking strategies used by Indonesian EFL learners in different situations taking into account social status and social distance as its contextual factors. Although many studies have been conducted to explore the speech act of thanking, little research is available on thanking strategies particularly the ones focusing on contextual factors.

\section{Theoretical Review: The Speech Act of Thanking}

Thanking or expressing gratitude is one of the acts under the category of expressive speech act. Expressive speech act primarily focuses on representing the speaker' feelings. In other words, speakers use expressive speech act to express their feelings by making their words fit their internal psychological world (Yule, 1996). Language speakers in any community can express gratitude through words of thanks, praise, compliment, or appreciation (Fishgadam \& Zarei, 2011 \& Dalilan, 2012). The first one to classify the speech act of thanking was Austin (1962 in Levinson, 1995) for whom it was a behabitive act, "a reaction to other people's behaviour and fortunes and of attitudes and expressions of attitudes to someone else's past conduct or imminent conduct." His disciple, Searle (1976 in Levinson 1995; see also Mey, 2001) classified it as an expressive act. With regard to the felicity conditions he established, the act of thanking would be described as in Table 1. 


\section{Thank (for)}

\begin{tabular}{ll}
\hline Propositional content & Past act $A$ done by $H$. \\
Preparatory & $A$ benefits $S$ and $S$ believes $A$ benefits $S$. \\
Sincerity & $S$ feels grateful or appreciative for $A$. \\
Essential & $\begin{array}{l}\text { Counts as an expression of gratitude or } \\
\text { appreciation. }\end{array}$ \\
Comments: & $\begin{array}{l}\text { Sincerity and essential rules overlap. } \\
\text { Thanking is just expressing gratitude in a } \\
\text { way that, e.g., promising is not just } \\
\text { expressing an intention. }\end{array}$ \\
\hline
\end{tabular}

( $S$ refers to speaker; $H$ refers to hearer; $A$ refers to act)

Leech (1983) describes thanking as a "convivial function" whose illocutionary goal coincides with the social goal of establishing and maintaining a polite and friendly social atmosphere. It can be categorized within what is known as absolute politeness, which reinforces positive politeness and as such, contributes to the harmonious development of social relationships between members of a community.

The literature is rich with empirical studies on the speech act of thanking. Some researchers focus on analyzing the functions of thanking in a specific culture and others paid more attention to the cross culture pragmatics and how speech acts differ cross culturally not only in the way they are realized, but also in their distribution, frequencies of occurrence and the functions they serve. For example, Díaz Pérez (2005) analysed the selection of the strategy used when expressing gratitude and the use of external modifiers in English both as a native and as a foreign language. De Pablos-Ortega (2010) studied the difference between Spanish and British conventions, stating that "in the Spanish culture, this speech act is not used as a routine answer in certain interactions (waiter-client, ticket inspector-passenger and seller-buyer)". Cheng (2010) studied on thanking in American and Asian cultures, the expression of gratitude is more common in the American culture, and it is also considered 
more mechanical than sincere as it is done for big as well as for small favours. Similar findings were reached by Cui (2012) when he investigated expressions of gratitude by American English native speakers and Asian advanced EFL and ESL students. Yoosefvand \& Rasekh (2014) investigated how native speakers of English and Persian use the expression of the expression of thanking in different situations, concluding that Persian native speakers use thanking strategies more than English native speakers.

Other investigations on how speech act of thanking is realized have also been widely conducted. For example, Yusefi, et al. (2015) investigated the thanking strategies among Kurdish speakers of Ilam based on gender and age. Hanami (2014) explored how Japanese and Indonesians express their feeling of gratitude to the situations of thanks specified by Coulmas's taxonomy of thanks (1981). Ozdemir \& Revani (2010) examined NNSs' production of speech acts of gratitude in an EFL context, specifically how Turkish and Iranian advanced speakers of English expressed gratitude in terms of strategy use and length of speech. Another study conducted by Ahar and Rasekh (2011) investigated the effect of status and size of imposition on the gratitude strategies of Persian and American speakers. In Iranian context, Farina and Suleiman (2009) did a pilot study and examined the speech act of gratitude among Iranian English as Foreign Language (EFL) learners through handling a written DCT to ten people and also examined whether EFL learners' L2 pragmatic competence was towards or away from the target language as the level of proficiency increases.

A contrastive analysis of interactions found in the textbooks and their realization in spontaneous dialogues has been researched as well (see Cheng, 2010, De Pablos-Ortega, 2011; and De Pablos-Ortega, 2015).

\section{Research Method}

\section{Subject}

The participants of this study were 50 semester three students studying at a state polytechnic in Bandung, Indonesia taking English for Business as their academic specialization. The rationale behind choosing university students as a source of data collection was a convenience of sampling as well as following from most of the prior studies on speech acts in which the participants had been university students. The participants involved 33 females and 17 males students with the average age of 19 years old. However, age and gender factors 
were ignored in this study since the primary concern of this study was on the realization of thanking strategies based on contextual factors i.e. social status and social distance.

\section{Research Design}

This study employed descriptive quantitative in which the data were numeric, collected through survey and presented in the form of frequency and percentage. As Cresswell (2004) points out that descriptive quantitative research involves collecting numeric data in order to answer questions regarding the participants and the data are collected through surveys, interviews, or observation.

\section{Research Instrument}

The research instrument used for this study was a modified version of Discourse Completion Task (DCT) developed by Cheng (2005). The DCT used in this study consisted of ten different scenarios which varied according to social status and familiarity (see Table 2). The scenarios contained the most common situations that learners may encounter in their college life and was written in Indonesian language. The participants were asked to express their response to each described situation in the provided blank space after each of the situations. The constructed DCT was intended to elicit information on thanking strategies paying particular attention to the contextual factors of interlocutor familiarity (i.e. social distance) and social status (i.e. power). Social status is defined as the degree to which the speaker with respect to the hearer due to a higher rank within an organization, professional status, or the hearer's need to have a particular duty or job performed (Hudson, Detmer and Brown 1995). Social distance refers to the degrees of familiarity between interlocutors - how familiar the two interlocutors are with each other (Brown \& Levinson, 1987).

Table 2. Description of DCT situations

\begin{tabular}{|c|c|c|c|c|c|c|c|c|c|c|}
\hline Situation & $\begin{array}{l}\text { Scattere } \\
\text { d notes }\end{array}$ & $\begin{array}{c}\text { Asking } \\
\text { directio } \\
n\end{array}$ & $\begin{array}{c}\text { Comput } \\
\text { er }\end{array}$ & $\begin{array}{c}\text { Fina } \\
1 \\
\text { exa } \\
\text { m }\end{array}$ & $\begin{array}{c}\text { Borrowin } \\
\text { g book }\end{array}$ & $\begin{array}{c}\text { Clas } \\
\text { s } \\
\text { note }\end{array}$ & $\begin{array}{l}\text { Drivin } \\
\mathrm{g} \\
\text { home }\end{array}$ & $\begin{array}{c}\text { Paper } \\
\text { extensio } \\
n\end{array}$ & $\begin{array}{c}\text { Recommlett } \\
\text { er }\end{array}$ & $\begin{array}{c}\text { Exam } \\
\text { rescedulin } \\
\mathrm{g}\end{array}$ \\
\hline $\begin{array}{l}\text { Social } \\
\text { status }\end{array}$ & $=$ & $=$ & $=$ & $=$ & $=$ & $=$ & $=$ & - & - & - \\
\hline $\begin{array}{l}\text { Familiarit } \\
\text { y }\end{array}$ & - & - & - & + & + & + & - & - & - & - \\
\hline
\end{tabular}




\section{Framework of Data Analysis}

After collecting the data via DCTs, responses were categorized based on the thanking strategies scheme proposed by Cheng (2005). Afterwards, each response was coded into semantic units. Semantic unit was the smallest, most complete unit of semantic information that could stand alone and be understood by itself. The descriptive statistics were employed in the presentation of results. The frequencies and percentages were used to analyze the data.

\section{Thanking strategies Taxonomy (Cheng, 2005)}

1. Thanking

Participants say "thank you" in three ways:

a.Thanking only by using the word "thank you" (e.g. Thanks a lot! Thank you very much!)

b. thanking by stating the favour (e.g. Thank you for your help!)

c. thanking and mentioning the imposition caused by the favour (e.g. Thank you for helping me collect the papers.)

2. Appreciation

a. using the word appreciate (e.g. I appreciate it!)

b. using the word "appreciate" and mentioning the imposition caused by the favour (e.g. I appreciate the time you spent for me.)

3. Positive feelings

a. by expressing a positive reaction to the favour giver (hearer) (e.g. You are a life saver!)

b. by expressing a positive reaction to the object of the favour (e.g. This book was really helpful!)

1. Apology

a. using only apologizing words (e.g. I'm sorry)

b. using apologizing words and stating the favour or the fact (e.g. I'm sorry for the problem I made! )

c. criticizing or blaming oneself (e.g. I'm such a fool!) d. expressing embarrassment (e.g. It's so embarrassing!)

2. Recognition of imposition

a. acknowledging the imposition (e.g. I know that you were not allowed to give me extra time!)

b. stating the need for the favour (e.g. I try not to ask for extra time, but this time I need it!)

c. diminishing the need for the favour (e.g. You didn't have to do that!)

3. Repayment

a. offering or promising service, money, food or goods (e.g. Next time it's my turn to pay!)

$b$. indicating indebtedness (e.g. I owe you one!)

c. promising future self-restraint or self-improvement (e.g. It won't happen again!)

d. praising

4. Others

Expressions that do not belong to the above strategies are categorized as other 
strategies. There are four subcategories under the other strategy:
a. here statement (e.g. Here you are!)
b. small talk (e.g. Your face is very familiar to me but I can't remember where I saw you. What do you study?)
c. leave-taking (e.g. Have a nice day!)
d. joking (e.g. Don't forget to pay again next time)

5. Alerters

In the thanking situations, alerters and address term are likely to occur in the same utterance. The alerters include:
a. attention getter (e.g. Hey, Hi, Well)
b. title (e.g. Dr., Professor! Sir!)
c. name (e.g. John, Mary)

\section{Research Finding and Analysis}

\section{The overall use of thanking strategies}

Table 3. Frequency of thanking strategies for Indonesian EFL Learners

\begin{tabular}{|l|c|c|}
\hline \multirow{2}{*}{ Strategy } & \multicolumn{2}{|c|}{ Subject (N=50) } \\
\cline { 2 - 3 } & Frequency & Percentage \\
\hline Thanking & 520 & $51 \%$ \\
\hline Appreciation & 6 & $1 \%$ \\
\hline Positive feelings & 92 & $9 \%$ \\
\hline Apology & 73 & $7 \%$ \\
\hline Recognition of imposition & 6 & $1 \%$ \\
\hline Repayment & 88 & $9 \%$ \\
\hline Others & 57 & $6 \%$ \\
\hline Alerters & 174 & $17 \%$ \\
\hline \multirow{2}{*}{ Total } & $\mathbf{1 0 1 6}$ & $\mathbf{1 0 0 \%}$ \\
\hline
\end{tabular}

Table 3 shows the overall distribution of the eight thanking strategies produced by Indonesian EFL learners. It can be seen from the table that thanking strategy was the most frequently used strategy among learners. The second most frequent strategy used was alerters (20\%), which was much higher than the third most frequent strategy of repayment $(10 \%)$ and the fourth most strategy of positive feelings (9\%) and repayment (9\%). This finding seems to conform the study conducted by Hanami (2014) who investigated the expressions of gratitude used by Japanese and Indonesian college students. In the context of thanking realization in Indonesia, she reported that the Indonesian preferred using thanking strategy which was 
expressed by the bald thank of 'makasih', 'terima kasih' and 'thanks' to express gratitude to someone who had done something good regardless of his/her age.

Interestingly, the preferred thanking strategies used by Indonesian learners to some extent were very much similar to those used by learners in other countries. In Iranian context, for example, most studies revealed that the most frequent gratitude strategies used were thanking and alerters (see Yusefi et al (2015); Yastami \& Rastegar (2014); Ozdemir and Rezvani, 2010; Pishgadam \& Zarei, (2011), Farni \& Suleiman (2009). Similar case also happened in Persia. Several studies on thanking strategies conducted in Persia showed that the most frequently occurred strategy in expressing gratitude used by Persian learners was 'thanking' strategy, followed by 'repayment' and 'positive feelings' strategy (see Yoosefvand \&Rasekh, 2014; Ahar \& Rasekh, 2011). In China, thanking and alerters strategy were preferred strategies employed among EFL learners (see Cheng, 2005, Cui 2012).

Therefore, it is sufficient to conclude that the speech act thanking is routine formula that can be found in all languages and that thanking strategy is obviously the most preferred strategy and universally used for expressing gratitude.

\section{The use of strategies by contextual variables}

As previously mentioned, this study attempted to explore thanking strategies used by EFL Indonesian learners taking into account the social power (i.e., relative power) and familiarity (i.e. how familiar the two interlocutors are with each other) as its contextual factors. The ten scenarios presented in DCT contained four scenarios represented equal status with high familiarity situations, three scenarios represented equal status with high familiarity situations, and three scenarios represented low status with low familiarity situations.

\section{Equal-status with low-familiarity situations}

The results of the study indicated that Indonesian EFL learners preferred using thanking (56\%), apology (11\%) and alerters (11\%) strategies to the person whom they were not familiar with, but shared equal status. This results seems in line with the study conducted by Cheng (2005) who explored the use of thanking strategy by native speakers of Chinese and native speakers of English. Cheng (2005) reported that native speakers of Chinese and native speakers of English used more thanking and apology strategies in the low-familiarity situations. This finding revealed that the use of thanking and apology strategies were mostly used in the situations within which the interlocutors shared equal-status but were not well acquainted. 
Table 4. Frequency of thanking strategies by equal-status with low-familiarity situations

\begin{tabular}{|l|c|c|}
\hline \multirow{2}{*}{\multicolumn{1}{c|}{ Strategy }} & \multicolumn{2}{|c|}{ Subject (N=50) } \\
\cline { 2 - 3 } & Frequency & Percentage \\
\hline Thanking & 211 & $56 \%$ \\
\hline Appreciation & 3 & $1 \%$ \\
\hline Positive feelings & 24 & $6 \%$ \\
\hline Apology & 43 & $11 \%$ \\
\hline $\begin{array}{l}\text { Recognition of } \\
\text { imposition }\end{array}$ & 3 & $1 \%$ \\
\hline Repayment & 29 & $8 \%$ \\
\hline Others & 24 & $6 \%$ \\
\hline Alerters & 41 & $11 \%$ \\
\hline Total & $\mathbf{3 7 8}$ & $\mathbf{1 0 0 \%}$ \\
\hline
\end{tabular}

\section{Equal-status with high-familiarity situations}

Table 5 indicated that the most frequent used of thanking strategies in equal-status with high familiarity situations were thanking (54\%) and positive feelings (18\%) strategies. This finding implied that whenever EFL learners received a favour from someone who shared the same status and they were familiar to each other well, the most preferred thanking strategies used were thanking and positive feelings. In this particular situation, learners seemingly expressed their gratitude by providing positive reaction to the favour giver or to the object of the favour. The evidence of this could be seen from the leaner's response to deal with final exam situation (item no. 4) presented in DCT.

Response: "Wow....... akhirnya aku dapat kuasai materi ini. Berkat bantuanmu aku jadi bisa Att. getter small talk positive feelings Makasih banyak ya .

\section{Thanking}

Table 5. Frequency of thanking strategies by equal-status with high-familiarity situations

\begin{tabular}{|l|c|c|}
\hline \multirow{2}{*}{ Strategy } & \multicolumn{2}{c|}{ Subject (N=50) } \\
\cline { 2 - 3 } & Frequency & Percentage \\
\hline Thanking & 157 & $54 \%$ \\
\hline Appreciation & 2 & $1 \%$ \\
\hline Positive feelings & 51 & $18 \%$ \\
\hline Apology & 5 & $2 \%$ \\
\hline Recognition of imposition & 0 & $0 \%$ \\
\hline Repayment & 27 & $9 \%$ \\
\hline Others & 27 & $9 \%$ \\
\hline Alerters & 22 & $8 \%$ \\
\hline Total & 291 & $100 \%$ \\
\hline
\end{tabular}




\section{Low-status with low-familiarity situations}

As shown in Table 6, among the eight categories, thanking strategy occurred most frequently accounting for $61 \%$ of the whole responses. The second strategy with the highest number of responses was repayment composing of $13 \%$ of responses. The third strategy with respect to frequency was apology which accounted for $10 \%$ of the responses. This finding indicated that learners would likely express their gratitude mostly with thanking, repayment and apology strategies in situations within which they had lower social position and were not quite familiar with. In other words, when receiving a big favor from someone of higher status, learners would show more gratitude toward those they do not know very well than to those they know well. Looking into what learners do to reciprocate the favor, mostly learners in the study preferred to promise the favor giver to do self-restraint or self-improvement.

Table 6. Frequency of thanking strategies by low-status with low-familiarity situations

\begin{tabular}{|l|c|c|}
\hline \multirow{2}{*}{\multicolumn{1}{|c|}{ Strategy }} & \multicolumn{2}{c|}{ Subject (N=50) } \\
\cline { 2 - 3 } & Frequency & Percentage \\
\hline Thanking & 152 & $61 \%$ \\
\hline Appreciation & 1 & $0 \%$ \\
\hline Positive feelings & 17 & $7 \%$ \\
\hline Apology & 25 & $10 \%$ \\
\hline $\begin{array}{l}\text { Recognition of } \\
\text { imposition }\end{array}$ & 3 & $1 \%$ \\
\hline Repayment & 32 & $13 \%$ \\
\hline Others & 7 & $3 \%$ \\
\hline Alerters & 11 & $4 \%$ \\
\hline & 248 & $100 \%$ \\
\hline
\end{tabular}

\section{Conclusion}

This study aimed at investigating thanking strategies employed by EFL learners in different situations. Findings of this study revealed that thanking, alerters (i.e., title) and repayment were regarded as the preferred strategies used by EFL Indonesian learners. The use of these strategies can somewhat be attributed to learners' cultural values. The Indonesian society is 
traditionally non-egalitarian and has a firm sense of social hierarchy and strong awareness of status differences. The value of non-egalitarian is reflected in the use of thanking strategies (e.g. terimakasih banyak Pak, Bu, Mas, Mbak) in their daily interactions. Further research is required to explore thanking strategy in terms of length of speech due to the fact that subject's response to a given situation may contain more than one thanking strategy; and thanking realization patterns.

\section{References}

Ahar, V. \& Rasekh, A. E. (2011). The effect of social status and size of imposition on the gratitude strategies of Persian and English Speakers. Journal of Language Teaching and Research 2, 120-128

Aijmer, K. 1996. Conversational Routines in English: Convention and Creativity. London: Longman.

Brown, P. \& Levinson, S. C. (1987). Politeness: Some Universals in Language Usage. Cambridge: Cambridge University Press.

Cheng, S. W. (2010). A corpus-based approach to the study of speech act of thanking. Concentric: Studies on Lingustics 36, 257-274

Cheng, S. W. 2005). An exploratory cross-sectional study of interlanguage pragmatic development of expressions of gratitude by Chinese learners of English. Dissertation, University of Iowa http://ir.uiowa.edu/etd/104.

Coulmas, F. (1981). "Poison to your soul": Thanks and apologies contrastively viewed. In F. Coulmas (Ed.), Conversational routine (pp. 69-91). The Hague, Netherlands: Mouton.

Creswell, J. W. (2004). Educational research: Planning, conducting, and evaluating quantitative and qualitative research (2nd ed.). Columbus, $\mathrm{OH}$ : Merrill Prentice Hall.

Cui, X. (20120. A cross-linguistic study on expressions of gratitude by native and non native English speakers. Journal of Language Teaching and Research 3, 753-760.

Dalilan. (2012). Strategies in expressing thanking in English realized by Indonesian Learners. Indonesian Journal of English Language Teaching 8, 51-71

De Pablo-Ortega.(2011). The Pragmatics of thanking reflected in the textbooks for teaching Spanish as a foreign language. Journal of Pragmatics 43, 2411-2433

De Pablos-Ortega, C. (2010). "Attitudes of English Speakers towards Thanking in Spanish". Pragmatics 20, 149-170.

De Pablos-Ortega. C. (2015). Thank you for a lovely day! Constrastive Thanking in Textbooks for Teaching English and Spanish as Foreign Languages. Soprag 3, 150-173

Díaz Pérez, F.J. (2005). "The Speech Act of Thanking in English. Differences between Native and Non-native Speakers' Behaviour". ES: Revista de filología inglesa 26, 91102.

Eisenstein, M. \& Bodman, J. W. (1986). "I very appreciate": Expressions of gratitude by native and nonnative speakers of American English. Applied Linguistics, 7, 167-185.

Farnia, M. \& Suleiman R. R. R.. (2009). "An interlanguage pragmatic study of expressions of gratitude by Iranian EFL Learners - A Pilot Study. Malaysian Journal Of ELT Research $5,108-140$

Hanami, Y. (2014). Cultural differences in the situations of expressing gratitude between Japanese and Indonesian college students. Dissertation. Tohoku University, Japan 
Hudson, T., Deitmer, E., \& Brown, J. (1995). Developing prototypic measures of crosscultural pragmatics. Honolulu: University of Hawaii at Manoa, Second Language Teaching and Curriculum Center.

Leech, G. (1983). Principles of pragmatics. London and New York: Longman.

Levinson, S. C. (1995). Pragmatics. Cambridge: Cambridge University Press

Mey, J. L. (2001). Pragmatics : An Introduction. Massachusetts. Blackwell Publishing

Ozdemir, C. \& Revani, S. A. (2010). Interlanguage pragmatics in action: Use of expressions of gratitude. Science Direct Journal. Procedia Social and Behavioural Sciences 3, 194 202

Pishghadam, R., \& Zarei, S. (2011). Expression of gratitude: a case of EFL learners. Review of European Studies, 3, 2, 140-149.

Yasami, F. \& Sanaz, R. (2014). The use of thanking strategies among Iranian EFL learners of different proficiency levels. Science Direct. Procedia-Social and Behavioral Sciences 98, 1926-1930

Yoosefvand, A. \& Rasekh, A., E. (2014). A comparative study of gratitude speech act between Persian and English learners. Journal of Applied Linguistics and Language Research. 1, 44-61

Yule, George. (1996). Pragmatics. Oxford: Oxford University Press

Yusefi, K., Gowhary, H., Azizifar. A., \& Esmaeli, Z. (2015). A Pragmatic analysis of thanking strategies among Kurdish speakers of ilam based on gender and age. Science Direct. Procedia-Social and Behaviora Sciences 199, 211-217 